\title{
PENTINGNYA PERAWAT MENGETAHUI TENTANG ISSU TERKAIT DENGAN KESELAMATAN PASIEN DI RUMAH SAKIT
}

\section{Maranti Syah}

\section{Email: marantisyah555@gmail.com}

\begin{abstract}
ABSTRAK
Latar Belakang: Isu keselamatan (safety) di era global saat ini menjadi pusat perhatian oleh dunia dari berbagai sektor, termasuk di sektor kesehatan. Isu keselamatan di sektor kesehatan terkait dengan rumah sakit salah satunya ialah keselamatan pasien. Terdapat berbagai macam seperti obat, tes dan prosedur, alat dengan teknologinya, bermacam jenis tenaga profesi dan non profesi di rumah sakit yang siap memberikan pelayanan kepada pasien selama 24 jam. Keberagaman dan kerutinan pelayanan tersebut apabila tidak dikelola dengan baik dapat menciptakan Kejadian Tidak Diharapkan (KTD). Keselamatan pasien dan mutu pelayanan kesehatan yang tinggi merupakan tujuan akhir yang selalu diharapkan oleh rumah sakit, manajer, tim penyedia pelayanan kesehatan, pihak jaminan kesehatan, serta pasien, keluarga dan masyarakat. Metode: metode yang dilakukan adalah menggunakan literature review. Hasil: perawat memiliki pengetahuan tentang issue terkait dengan keselamatan pasien di rumah sakit.
\end{abstract}

\section{Kata Kunci: Perawat, Issu, Keselamatan Pasien, Rumah Sakit.}

\section{LATAR BELAKANG}

Mutu pelayanan yang berkualias dan didampingi dengan jaminan keselamatan pasien yang tinggi akan menghasilkan citra atau mutu rumah sakit yang baik dimata pasien sebagai konsumen rumah sakit. Nilai keselamatan pasien ialah hal yang sangat penting untuk diterapkan dan ditanamkan pada setiap anggota organisasi, dikarenakan patient safety adalah hal yang fundamental. Pemahaman yang baik terkait dengan keselamatan pasien akan menjadikan setiap anggota organisasi mengetahui apa yang akan dilakukan. Perilaku tersebut pada akhirnya menjadi suatu implementasi yang tertanam pada setiap anggota organisasi berupa perilaku Implementasi keselamatan pasien.

Rumah sakit merupakan sarana pelayanan kesehatan yang dibutuhkan ketika seseorang sakit dan membutuhkan bantuan dengan tujuan untuk dapat menyelamatkan kondisi pasien. Dengan berlalunya waktu dan perkembangan ilmu pengetahuan dan 
teknologi rumah sakit tidak hanya menjadi tempat untuk menyelamatkan pasien. Berbagai layanan dapat diakses pasien yang membutuhkan bantuan. Pasien yang memerlukan bantuan menyeluruh dan secara intensif selama 24 jam dapat mengakses layanan rawat inap. Perawatan rawat inap mempunyai peran penting dalam pelayanan perawatan untuk observasi, diagnosis, pengobatan atau upaya perawatan kesehatan lainnya.

Perawat ialah pejabat eksekutif kesehatan dengan waktu kerja tertinggi yang memberikan 24 jam pelayanan terus menerus serta harus berkolaborasi dengan tim kesehatan lainnya. Oleh karena itu halhal tersebut dapat menimbulkan atau berisiko terjadinya Insiden Keselamatan Pasien. Selain itu, perawat mempunyai peran yang paling dominan dalam mencegah terjadinya kesalahan dalam pengobatan, termasuk pelaporan insiden, mendidik diri sendiri dan orang lain. Sejalan dengan definisi keperawatan ANA 2003 yang mengatakan bahwa keperawatan merupakan perlindungan, promosi, dan optimalisasi kesehatan dan kemampuan, pencegahan penyakit dan cedera, pengentasan penderitaan melalui diagnosis dan pengobatan respon manusia, dan advokasi dalam perawatan individu, keluarga, masyarakat, dan populasi.
Isu keselamatan pasien menciptakan paradigma baru tentang mutu pelayanan. Mutu pelayanan yang baik saja tidak cukup berarti terhadap pasien tanpa memperhatikan bagaimana derajat unsur resiko dan keselamatan yang diterima oleh pasien. Tinggi rendahnya mutu sebanding dengan tingkat dari ketersediaan fasilitas pelayanan, untuk dapat mencapai keseimbangan terbaik antara risiko dan manfaat keselamatan yang diterima oleh pasien.

Gerakan (Patient Safety) keselamatan pasien sudah menjadi spirit dalam pelayanan rumah sakit di seluruh dunia tidak hanya rumah sakit di negara maju saja yang menerapkan keselamatan pasien untuk menjamin mutu pelayanan, tetapi juga rumah sakit di negara berkembang seperti di Indonesia (Depkes, 2006).

Keselamatan pasien (patient safety) merupakan suatu sistem dimana rumah sakit membuat asuhan pasien lebih aman dalam upaya untuk dapat mencegah terjadinya cidera yang disebabkan oleh kesalahan akibat dari melaksanakan suatu tindakan atau tidak mengambil tindakan yang seharusnya diambil. Menurut Komite Keselamatan Pasien Rumah Sakit tahun 2008, keselamatan pasien ialah suatu kondisi dimana pasien bebas dari cedera yang tidak seharusnya terjadi yang masih dapat dihindari atau bebas dari risiko dan 
cidera yang berpotensial akan mungkin terjadi.

Berdasarkan dari Peraturan Menteri Kesehatan Republik Indonesia Nomor 11 Tahun 2017, keselamatan pasien adalalah suatu system yang membuat asuhan pasien lebih aman, meliputi asesmen risiko, identifikas, dan pengelolaan risiko pada pasien, pelaporan dan analisis insiden, keterampilan belajar dari insiden dan tindak lanjutnya, serta implementasi solusi untuk meminimalkan timbulnya risiko dan juga dapat mencegah terjadinya cidera yang disebabkan oleh kesalahan akibat melaksanakan suatu tindakan atau tidak mengambil tindakan yang seharusnya diambil.

Rumah sakit sebagai instansi pelayanan kesehatan yang berhubungan langsung dengan pasien harus memprioritaskan pelayanan kesehatan yang aman, bermutu, antidiskriminasi dan efektif dengan mengutamakan kepentingan pasien yang sesuai dengan standar pelayanan rumah sakit . Pasien sebagai pengguna pelayanan kesehatan berhak mendapatkan keamanan dan keselamatan dirinya selama dalam perawatan di rumah sakit.

Kementerian Kesehatan Republik Indonesia telah mengeluarkan Peraturan Menteri Kesehatan No. 11 Tahun 2017 tentang Keselamatan Pasien di Rumah
Sakit. Peraturan ini menjadi tonggak utama operasionalisasi keselamatan pasien di rumah sakit seluruh Indonesia. Banyak rumah sakit di Indonesia yang sudah berupaya dalam membangun dan mengembangkan keselamatan pasien, namun upaya tersebut dilaksanakan berdasarkan pemahaman manajemen terhadap keselamatan pasien. Peraturan menteri ini memberikan panduan bagi manajemen rumah sakit agar dapat menjalankan spirit keselamatan pasien secara utuh.

\section{METODE}

Metode yang digunakan adalah literature riview. Menggunakan analisis data dari berbagai sumber untuk menguraikan suatu masalah dan mengevaluasi masalah tersebut dan merangkum menjadi suatu pembahasan untuk menyelesaikan masalah tersebut. Literatur review merupakan uraian tentang teori, temuan, serta bahan penelitian lain yang didapatkan dari bahan acuan untuk dijadikan sebagai landasan kegiatan penelitian untuk menyusun kerangka pemikiran yang jelas dari perumusan masalah yang ingin di teliti.

Metode ini memberikan gambaran mengenai bagaimana penerapan keselamatan pasien oleh perawat dirumah sakit yang sampai saat ini masih di anggap sepele oleh perawat sebagai pemberi 
layanan kesehatan. Metode ini memberikan penjelasan dan pembahasan dalam penerapan keselamatan pasien oleh perawat yang dapat mempengaruhi kualitas pelayanan kesehatan di rumah sakit.

\section{HASIL}

Isu keselamatan (safety) di era global saat ini menjadi pusat perhatian oleh dunia dari berbagai sektor, termasuk di sektor kesehatan. Isu keselamatan di sektor kesehatan terkait dengan rumah sakit salah satunya ialah keselamatan pasien. Terdapat berbagai macam seperti obat, tes dan prosedur, alat dengan teknologinya, bermacam jenis tenaga profesi dan non profesi di rumah sakit yang siap memberikan pelayanan kepada pasien selama 24 jam.

Penerapan keselamatan pasien dilakukan dengan baik maka pelayanan yang memprioritaskan keselamatan dan kualitas yang optimal akan memberikan dampak yang luas. Terutama bagi masyarakat akan mendapatkan pelayanan yang lebih berkualitas, aman dan memenuhi harapan mereka. Bagi rumah sakit menjadi nilai plus untuk pencapaian pelayanan yang berstandar nasional dan internasional. Pelayanan yang aman dan kualitas juga diharapkan dapat menumbuhkan kepercayaan publik kepada rumah sakit.
Bagi tenaga kesehatan dapat menciptakan nilai-nilai baru khususnya arti penting penerapan keselamatan pasien dalam setiap aktivitas pelayanan yang diberikan (Agency for Healthcare Research and Quality/AHRQ, 2015).

Pelatihan dalam lingkup mutu dan keselamatan adalah salah satu sarana untuk menambah kebutuhan akan pengetahuan baru dan untuk meningkatkan kinerja individu dan kinerja system (Henriksen \& Dayton,2006). Keselamatan pasien rumah sakit merupakan suatu system dimana rumah sakit membuat asuhan pasien lebih aman yang melputi assesmen resiko, identifikasi dan pengelolaan hal yang berhubungan dengan risiko pasien, pelaporan dan analisi insiden, kemampuan belajar dari insiden dan tindak lanjutnya serta implementasi solusi untuk meminimalkan timbulnya risiko dan mencegah terjadinya cedera yang disebabkan oleh kesalahan akibat dari melaksanakan suatu tindakan atau tidak mengambil tindakan yang seharusnya di ambil (Permenkes No. $1691,2011)$.

\section{PEMBAHASAN}

Keselamatan pasien ialah prinsip dasar dalam pelayanan kesehatan. Menurut Depkes RI (2008) Keselamatan pasien (patient safety) rumah sakit merupakan 
suatu sistem dimana rumah sakit membuat asuhan pasien lebih yang aman. Sistem tersebut meliputi: assessmen risiko, identifikasi dan pengelolaan hal yang berhubungan dengan risiko pasien, pelaporan dan analisis insiden, kemampuan belajar dari insiden dan tindaklanjutnya serta implementasi solusi untuk meminimalkan timbulnya risiko. Sistem tersebut diharapkan mampu mencegah terjadinya cedera yang disebabkan oleh kesalahan akibat melaksanakan suatu tindakan atau tidak melakukan tindakan yang seharusnya dilakukan.

Salah satu tujuan dari keselamatan pasien ialah menurunnya KTD yang merupakan bagian dari insiden keselamatan pasien. Untuk mencapai tujuan tersebut, maka disusunlah Sasaran Keselamatan pasien yang bertujuan agar dapat mendorong perbaikan spesifik dalam keselamatan pasien. Sasaran menyoroti bagian-bagian yang bermasalah dalam pelayanan kesehatan dan dapat menjelaskan bukti serta solusi dari konsensus berbasis bukti dan keahlian atas permasalahan yang telah ada. Penyusunan sasaran ini mengacu kepada Nine Life-Saving Patient Safety Solutions dari WHO Patient Safety (2007) yang digunakan juga oleh Komite Keselamatan Pasien Rumah Sakit PERSI
(KKPRS PERSI), dan dari Joint Commission International (JCI).

Oleh karena itu, jika rumah sakit ingin meminimalkan kejadian insiden keselamatan pasien maka rumah sakit haruslah menerapkan budaya keselamatan pasien. Sampai saat ini, banyak negara yang telah memulai penelitian budaya keselamatan pasien, baik Negara maju maupun Negara berkembang seperti Indonesia. Penelitian tentang budaya keselamatan pasien sudah berkembang dalam beberapa tahun terakhir. Namun, masih kurang evaluasi objektif dan kuantitatif dari segi kualitas penelitianpenelitian tersebut.

Isu penting terkait keselamatan di rumah sakit (RS) ialah: keselamatan pasien, keselamatan pekerja atau petugas kesehatan, keselamatan bangunan dan peralatan di rumah sakit yang berdampak terhadap keselamatan pasien dan petugas, keselamatan lingkungan yang berdampak kepada pencemaran lingkungan, dan keselamatan "bisnis" rumah sakit terkait dengan kelangsungan hidup rumah sakit.

Patient safety adalah istilah yang saat ini cukup populer dalam pelayanan kesehatan. Patient safety ialah upaya-upaya pelayanan yang memprioritaskan pada keselamatan pasien. Keselamatan pasien (patient safety) merupakansuatu sistem dimana rumah 
sakit membuat asuhan pasien lebih aman, mencegah terjadinya cidera yang dikarenakan oleh kesalahan akibat melaksanakan suatu tindakan atau tidak mengambil tindakan yang seharusnya diambil.

Keselamatan pasien di rumah sakit melibatkan partisipasi dari semua petugas kesehatan, terutama adalah perawat. Perawat sebagai salah satu tenaga kesehatan yang memiliki jumlah cukup dominan di rumah sakit yaitu sebesar 50 sampai $60 \%$ dari jumlah tenaga kesehatan yang ada. Pelayanan asuhan keperawatan yang diberikan kepada pasien ialah pelayanan yang terintegrasi dari pelayanan kesehatan yang lainnya dan memiliki peran yang cukup penting bagi terciptanya kesehatan dan keselamatan pasien.

Insiden Keselamatan Pasien ialah peristiwa dan kondisi yang tidak disengaja yang menyebabkan atau berpotensi mengakibatkan cedera yang dapat dicegah pada pasien, Insiden Keselamatan Pasien (IKP) yang terdiri dari Kejadian Tidak Diharapkan (KTD), Kejadian Nyaris Cedera (KNC), Kejadian Tidak Cedera (KTC) dan Kondisi Potensial Cedera (KPC). Keselamatan pasien yakni prioritas utama dan harus segera dilakukan di rumah sakit karena dapat mengakibatkan cedera langsung kepada pasien, juga terkait dengan kualitas dan citra rumah sakit serta standar pelayanan yang harus dipenuhi oleh rumah sakit itu terkait dengan versi 2012 dari standar akreditasi mengacu pada Joint Commission International (JCI).

keselamatan merupakan output dari individu dan kelompok terhadap nilainilai, sikap, kompetensi, dan pola dan kebiasaan yang menggambarkan komitmen, gaya serta kemampuan organisasi dan manajemen keselamatan kesehatan. Budaya keselamatan pasien adalah suatu hal yang penting karena membangun budaya keselamatan pasien merupakan suatu cara untuk dapat membangun program keselamatan pasien secara keseluruhan, karena apabila kita lebih fokus pada budaya keselamatan pasien maka akan lebih mendapatkan hasil keselamatan yang lebih apabila dibandingkan hanya menfokuskan pada programnya saja.

World Health Organization (WHO) mengatakan keselamatan pasien ialah masalah kesehatan masyarakat global yang serius. Kesalahan medis dapat dihasilkan oleh faktor sistem dan faktor manusia. Insiden keselamatan pasien yang merugikan yakni terkait dengan prosedur bedah (27\%), kesalahan pengobatan $(18,3 \%)$ dan kesehatan infeksi terkait perawatan (12,2\%) (WHO, 2017). Sedangkan di Eropa, kejadian pasien 
dengan risiko infeksi sebanyak $83,5 \%$ dan bukti kesalahan medis menunjukkan 50$72,3 \%$.

Keselamatan menjadi isu global yang terangkum dalam lima isu penting terkait di rumah sakit yaitu keselamatan pasien, keselamatan pekerja atau petugas kesehatan, keselamatan bangunan dan peralatan di rumah sakit yang bisa berdampak terhadap keselamatan pasien dan petugas. Keselamatan lingkungan yang berdampak kepada pencemaran lingkungan dan keselamatan bisnis rumah sakit yang terkait dengan kelangsungan hidup rumah sakit. Keselamatan pasien juga merupakan prioritas utama untuk dilaksanakan terkait dengan isu mutu dan citra perumahsakitan.

Berdasarkan Permenkes No. 46 Tahun 2015, bahwa fasilitas kesehatan diwajibkan memperhatikan mutu pelayanan dan keselamatan pasien dalam setiap kegiatan pelayanan dan dilakukan secara berkesinambungan. Berdasarkan penelitian Firawati, dkk. (2012), pelaksanaan keselamatan pasien dan budaya keselamatan pasien di sebuah fasilitas pelayanan kesehatan dapat dipengaruhi oleh beberapa faktor yaitu pengorganisasian, lingkungan kerja, dan faktor budaya. Dalam pelaksanannya, upaya keselamatan pasien memerlukan pemantauan yang berkesinambungan agar pelaksanaannya sesuai dengan tujuan dan standar-standar yang telah ditentukan. Berdasarkan penelitian Samra, R., dkk. (2016), bahwa terdapat beberapa strategi monitoring yang bisa digunakan sebagai metode pemantauan dalam implementasi upaya keselamatan pasien. Strategi monitoring yang digunakan dapat disesuaikan dengan kebutuhan, kemampuan dan kondisi fasilitas pelayanan kesehatan yang ada.

Program keselamatan pasien merupakan suatu usaha untuk menurunkan angka Kejadian Tidak Diharapkan (KTD) yang sering terjadi pada pasien selama dirawat di rumah sakit sehingga dapat merugikan baik pasien itu sendiri maupun pihak rumah sakit. KTD bisa dikarenakan oleh berbagai faktor, antara lain : beban kerja perawat yang tinggi, alur komunikasi yang kurang tepat, penggunaan sarana kurang tepat dan sebagainya (Nursalam, 2014). Secara keseluruhan program patient safety telah diterapkan, namun masalah dilapangan merujuk pada konsep patient safety, karena walaupun sudah pernah mengikuti sosialisasi, tetapi masih ada pasien yang cidera, resiko jatuh, resiko salah pengobatan, pendelegasian yang tidak akurat saat oforan pasien yang mengakibatkan keselamatan pasien menjadi kurang maksimal (Bawelle et al., 2013). 
Rumah Sakit (RS) merupakan institusi pelayanan kesehatan bagi masyarakat dengan karateristik tersendiri yang dipengaruhi oleh perkembangan ilmu pengetahuan kesehatan, kemajuan teknologi, dan kehidupan sosial ekonomi masyarakat yang harus tetap mampu menghasilkan pelayanan yang lebih bermutu dan terjangkau oleh masyarakat agar terwujudnya derajat kesehatan yang setinggi-tingginya, seperti yang dijelaskan dalam UndangUndang Kesehatan Nomor 36 Tahun 2009 dan Undang-Undang Rumah Sakit Nomor 44 Tahun 2009 bahwa rumah sakit wajib melaksanakan pelayanan kesehatan yang aman, bermutu, anti diskriminasi dan efektif, dengan memprioritaskan kepentingan pasien. Rumah sakit harus memenuhi hak pasien memperoleh keamanan dan keselamatan selama dalam perawatan di rumah sakit. (Permenkes RI Nomor 1961/Menkes/2011).

\section{PENUTUP}

Keselamatan pasien (patient safety) merupakan suatu sistem dimana rumah sakit membuat asuhan pasien lebih aman dalam upaya untuk dapat mencegah terjadinya cidera yang disebabkan oleh kesalahan akibat dari melaksanakan suatu tindakan atau tidak mengambil tindakan yang seharusnya diambil.
Isu penting terkait keselamatan di rumah sakit (RS) ialah: keselamatan pasien, keselamatan pekerja atau petugas kesehatan, keselamatan bangunan dan peralatan di rumah sakit yang berdampak terhadap keselamatan pasien dan petugas, keselamatan lingkungan yang berdampak kepada pencemaran lingkungan, dan keselamatan "bisnis" rumah sakit terkait dengan kelangsungan hidup rumah sakit.

\section{REFRENSI}

Hakim, L. Dkk. (2014). Optimalisasi Proses Koordinasi Program Keselamatan Pasien (Patient Safety) Di Rumah Sakit X Surabaya. Jurnal Administrasi Kesehatan Indonesia. 2(3):198208.

Herawati, Y. T. (2015). Budaya Keselamatan Pasien Di Ruang Rawat Inap Rumah Sakit X Kabupaten Jember. Jurnal IKESMA. 11(1):52-60.

Juniarti, N. H. Mudayana, A. A. (2018). Penerapan Standar Keselamatan Pasien Di Rumah Sakit Umum Daerah Provinsi Nusa Tenggara Barat. Jurnal Kesehatan Poltekkes Ternate. 11(2):93-108.

Najihah. (2018). Budaya Keselamatan Pasien Dan Insiden Keselamatan 
Pasien Di Rumah Sakit: Literature

Review. Journal of Islamic

Nursing. 3(1):1-8.

Neri, R. A. (2018). Analisis Pelaksanaan

Sasaran Keselamatan Pasien Di

Rawat Inap Rumah Sakit Umum

Daerah Padang Pariaman. Jurnal

Kesehatan Andalas. 7(4):48-55.

Salawati, L. (2020). Penerapan

Keselamatan Pasien Rumah Sakit.

Jurnal Averrous. 6(1):98-107

Simamora, R. H., \& Nurmaini, C. T. S. (2019). Knowledge of Nurses about Prevention of Patient Fall Risk in Inpatient Room of Private Hospital in Medan. Indian Journal of Public Health Research \& Development, 10(10), 759-763.

Sumarni. (2017). Analisis Implementasi Patient Safety Terkait Peningkatan Mutu Pelayanan Kesehatan di Rumah Sakit. Jurnal Ners dan Kebidanan Indonesia. 5(2):91-99.

Triwibowo, C. (2016). Handover Sebagai Upaya Peningkatan Keselamatan Pasien (Patient Safety) Di Rumah Sakit. Jurnal Keperawatan Soedirman (The Soedirman Journal of Nursing). 11(2):76-80.

Utarini, A. Djars, H. (2012). Keselamatan Pasien Dan Mutu Pelayanan
Kesehatan: Menuju Kemana?. Jurnal Manajemen Pelayanan Kesehatan. 15(4):159-160.

Yusuf, M. (2017). Penerapan Patient Safety Di Ruang Rawat Inap Rumah Sakit Umum Daerah Dr. Zainoel Abidin. Jurnal Ilmu Keperawatan. 5(1):85-89. 
